\section{Response to 'IgA vasculitis in adults: few certainties and many uncertainties' by Hočevar et al}

We thank Hočevar and colleagues for their comments on our recently published work on the epidemiology of IgA vasculitis (IgAV) in adults and children. ${ }^{12}$ We agree that there is some uncertainty regarding the incidence of adult-onset IgAV as this has not previously been widely studied.

Our calculated incidence of 2.20 (95\% CI 2.08 to 2.37) per 100 000 person-years in adults is slightly higher than most previous work has suggested, but is lower than that reported by Hočevar et al in a Slovenian tertiary centre study with no clearly demarcated denominator population. ${ }^{2-4}$ This disparity may be related to interpopulation differences, for example, in exposure to environmental risk factors such as viral infections. ${ }^{5}$ Alternatively, the difference may be due to contrasting strategies used to identify cases of IgAV. Hočevar and colleagues used both clinical and pathological records to identify cases, thus reducing the risk of missing patients who had not been appropriately coded. A strength of our estimate is that it derives from a nationally representative population-based study. Nevertheless, the absolute risk is very small (2-5 per 100 000 person-years) and therefore the dissimilarity should be interpreted with caution.

We agree that some patients may receive clinical codes inappropriately despite not having a diagnosis of IgAV, and conversely that some individuals with IgAV may not have the diagnosis documented. Rather than relying on a single code, we used a comprehensive list to identify individuals with IgAV and reduce the risk of missing cases. Nevertheless, it is likely that some cases were not captured by this method. The cited work by Deshayes et al highlights potential pitfalls of using clinical codes. ${ }^{6}$ However, this was from a single-centre study evaluating a different coding structure in a separate healthcare system to ours and is therefore not directly applicable.

It is notable that Hočevar and colleagues' cohort had a much higher age at IgAV diagnosis than our cohort. However, our cohort's mean age of diagnosis was closer to previous reports. ${ }^{7-9}$ The adult-onset IgAV cohort did have an unexpectedly equal gender distribution, although our data show a trend towards higher incidence of hypertension (adjusted HR (aHR) 1.51, 95\% CI 1.19 to 1.91 vs aHR $1.30,95 \%$ CI 0.99 to 1.71 ) and chronic kidney disease (CKD; aHR 2.04, 95\% CI 1.43 to 2.92 vs aHR $1.23,95 \%$ CI 0.91 to 1.66 ) in men compared with women. It is possible that men tend to present with more severe disease and have therefore been over-represented in hospital-based IgAV cohorts.

We note with interest the baseline characteristics reported by Hočevar et al for their cohort of patients with IgAV, which reinforces some patterns we observed in our own data. The higher burden of baseline comorbidities for individuals who develop IgAV is intriguing, and the cause of this association is unclear.

Notably, our analyses were adjusted for baseline comorbidities including obesity, diabetes and dyslipidaemia, so these do not explain the increased incidence of hypertension and CKD observed in patients with IgAV. In addition, the observed associations were robust when our analysis was restricted to CKD or hypertension recorded at least 1 year after each participant's index date. This suggests that renal impairment and hypertension are not solely features of the acute illness. The mechanism underlying this association may involve secondary factors such as intraglomerular hypertension, glomerular hypertrophy and proteinuria. However, investigation of this was beyond the scope of our study.
There are many opportunities for further study of IgAV in adults. The incidence of this disease is not well characterised, and further population-based research will be required to clarify this. The high baseline prevalence of hypertension and diabetes mellitus in the described adult IgAV cohorts is currently unexplained. Explanation of this association may offer opportunities for interventions that improve long-term health outcomes in these patients.

Alexander Tracy $\odot,{ }^{1}$ Anuradhaa Subramanian, ${ }^{2}$ Nicola J Adderley, ${ }^{2}$ Lorraine Harper, ${ }^{1}$ Krishnarajah Nirantharakumar $^{2}$

${ }^{1}$ Institute of Clinical Sciences, Centre for Translational Inflammation Research, University of Birmingham Research Laboratories, Queen Elizabeth Hospital Birmingham, Birmingham, UK

${ }^{2}$ Institute of Applied Health Research, University of Birmingham, Birmingham, UK

Correspondence to Dr Lorraine Harper, Institute of Clinical Sciences, Centre for Translational Inflammation Research, University of Birmingham Research Laboratories, Queen Elizabeth Hospital Birmingham, Birmingham B15 2WB, UK; I.harper@bham.ac.uk

\section{Handling editor Josef $S$ Smolen}

Contributors AT, AS, NJA, LH and KN wrote the article and revised for intellectual content. All authors approved the final version to be submitted for review. LH and $\mathrm{KN}$ contributed equally to this work.

Competing interests None declared.

Patient consent for publication Not required.

Provenance and peer review Commissioned; internally peer reviewed.

(c) Author(s) (or their employer(s)) 2020. No commercial re-use. See rights and permissions. Published by BMJ.

$\mathrm{LH}$ and $\mathrm{KN}$ contributed equally.

\section{Check for updates}

To cite Tracy A, Subramanian A, Adderley NJ, et al. Ann Rheum Dis 2020;79:e48.

Received 11 January 2019

Accepted 11 January 2019

Published Online First 30 January 2019

\section{Linked}

- http://dx.doi.org/10.1136/annrheumdis-2018-214907

Ann Rheum Dis 2020;79:e48. doi:10.1136/annrheumdis-2018-214951

ORCID iD

Alexander Tracy http://orcid.org/0000-0003-4109-3568

\section{REFERENCES}

1 Hočevar A, Tomšič M, Rotar Ž. Iga vasculitis in adults: few certainties and many uncertainties. Ann Rheum Dis 2020;79:e47.

2 Tracy A, Subramanian A, Adderley NJ, et al. Cardiovascular, thromboembolic and renal outcomes in IgA vasculitis (Henoch-Schönlein purpura): a retrospective cohort study using routinely collected primary care data. Ann Rheum Dis 2020;79:261-9.

3 Piram M, Mahr A. Epidemiology of immunoglobulin A vasculitis (Henoch-Schönlein): current state of knowledge. Curr Opin Rheumatol 2013;25:171-8.

4 Hočevar A, Rotar Z, Ostrovršnik J, et al. Incidence of IgA vasculitis in the adult Slovenian population. Br J Dermatol 2014;171:524-7.

5 Hwang HH, Lim IS, Choi BS, et al. Analysis of seasonal tendencies in pediatric HenochSchönlein purpura and comparison with outbreak of infectious diseases. Medicine 2018:97:e12217.

6 Deshayes $\mathrm{S}$, Moulis G, Pillebout E, et al. Positive predictive value of hospital discharge diagnosis code to identify immunoglobulin A vasculitis in France: a validation study. Eur J Intern Med 2017;43:e18-19.

7 Pillebout E, Thervet E, Hill G, et al. Henoch-Schönlein purpura in adults: outcome and prognostic factors. J Am Soc Nephrol 2002;13:1271-8.

8 Hong S, Ahn SM, Lim DH, et al. Late-onset IgA vasculitis in adult patients exhibits distinct clinical characteristics and outcomes. Clin Exp Rheumatol 2016;34(3 Suppl 97):S77-83.

9 Uppal SS, Hussain MA, Al-Raqum HA, et al. Henoch-Schönlein's purpura in adults versus children/adolescents: a comparative study. Clin Exp Rheumatol 2006;24(2 Suppl 41):S26-30. 